University of Nebraska - Lincoln

DigitalCommons@University of Nebraska - Lincoln

USDA National Wildlife Research Center - Staff Publications
U.S. Department of Agriculture: Animal and Plant Health Inspection Service

2011

\title{
Annual Seroprevalence of Yersinia pestis in Coyotes as Predictors of Interannual Variation in Reports of Human Plague Cases in Arizona, United States
}

\author{
Heidi E. Brown \\ Centers for Disease Control and Prevention \\ Craig E. Levy \\ Arizona Department of Health Services \\ Russell E. Enscore \\ Centers for Disease Control and Prevention \\ Martin E. Schriefer \\ Centers for Disease Control and Prevention \\ Thomas J. DeLiberto \\ USDA/APHIS/WS National Wildlife Research Center, Thomas.J.DeLibertot@aphis.usda.gov \\ See next page for additional authors
}

Follow this and additional works at: https://digitalcommons.unl.edu/icwdm_usdanwrc

Brown, Heidi E.; Levy, Craig E.; Enscore, Russell E.; Schriefer, Martin E.; DeLiberto, Thomas J.; Gage, Kenneth L.; and Eisen, Rebecca J., "Annual Seroprevalence of Yersinia pestis in Coyotes as Predictors of Interannual Variation in Reports of Human Plague Cases in Arizona, United States" (2011). USDA National Wildlife Research Center - Staff Publications. 1293.

https://digitalcommons.unl.edu/icwdm_usdanwrc/1293

This Article is brought to you for free and open access by the U.S. Department of Agriculture: Animal and Plant Health Inspection Service at DigitalCommons@University of Nebraska - Lincoln. It has been accepted for inclusion in USDA National Wildlife Research Center - Staff Publications by an authorized administrator of DigitalCommons@University of Nebraska - Lincoln. 


\section{Authors}

Heidi E. Brown, Craig E. Levy, Russell E. Enscore, Martin E. Schriefer, Thomas J. DeLiberto, Kenneth L. Gage, and Rebecca J. Eisen 


\title{
Annual Seroprevalence of Yersinia pestis in Coyotes as Predictors of Interannual Variation in Reports of Human Plague Cases in Arizona, United States
}

\author{
Heidi E. Brown, ${ }^{1, *}$ Craig E. Levy, ${ }^{2}$ Russell E. Enscore,' Martin E. Schriefer,' Thomas J. DeLiberto, ${ }^{3}$ \\ Kenneth L. Gage, and Rebecca J. Eisen ${ }^{1}$
}

\begin{abstract}
Although several health departments collect coyote blood samples for plague surveillance, the association between reported human cases and coyote seroprevalence rates remains anecdotal. Using data from an endemic region of the United States, we sought to quantify this association. From 1974 to 1998, about 2,276 coyote blood samples from four Arizona counties were tested for serological evidence of exposure to Yersinia pestis, the causative agent of plague. Using a titer threshold presumed to be indicative of recent infection (serum titers of $\geq 1: 256$ ), we found a statistically significant relationship between years with $>17 \%$ sero-positive coyotes and years with two or more human cases reported. Moreover, when the annual coyote seroprevalence rates were dichotomized at $17 \%, 84 \%$ of the years were correctly classified using four biologically relevant meteorological variables in a linear regression. This is the first time a statistically significant temporal association between human plague cases and coyote seroprevalence rates has been shown. However, issues with data resolution and surveillance effort that potentially limit the public health utility of using coyote seroprevalence rates are discussed.
\end{abstract}

Key Words: Arizona—Coyote seroprevalence rates—Meteorology—Plague—Yersinia pestis.

\section{Introduction}

$\mathbf{P}$ LAGUE IS A SEVERE, primarily flea-borne zoonotic disease caused by the bacterium Yersinia pestis. It is characterized by long periods of quiescence punctuated by rapidly spreading epizootics. During epizootics, the risk for human exposure increases because some species of infected fleas that abandon their rodent hosts, after they succumb to plague infection, will readily feed on humans (Gage and Kosoy 2005). Of the 456 cases of plague reported to the Centers for Disease Control and Prevention (CDC) from 1950 through 2008, 67.5\% of cases occurred in either New Mexico $(n=245)$ or Arizona $(n=63)$ (CDC, unpublished data). Although the frequency of disease is low, with an average of 8 (range: 1-40) human cases reported annually in the United States from 1950 through 2008 (CDC, unpublished data), case fatality rates are high if appropriate antibiotic therapy is delayed or inadequate (Hull et al. 1986, MMWR 2006). Improvements in our ability to identify when and where plague risk is greatest can be helpful to target surveillance activities, raise awareness of the disease among both healthcare providers and the public, issue public health prevention messages, and may ultimately shorten the time to treatment through more rapid diagnosis and thus improve outcome of infection.

Coyotes and other canids are not widely believed to serve as reservoirs of plague bacteria (Barnes 1982), and the very few human infections directly linked with exposure to predators were associated with direct contact with infectious carcasses in the absence of proper personal protective equipment (Poland et al. 1973, von Reyn et al. 1976, Wong et al. 2009). Nonetheless, coyotes and other carnivores are potential sentinels of increases in plague activity because of their contact with potentially infectious small mammals and because they often survive plague infection and seroconvert (Archibald and Kunitz 1971, Willeberg et al. 1979, Gage et al. 1994, Salkeld and Stapp 2006).

\footnotetext{
${ }^{1}$ Division of Vector-Borne Diseases, Centers for Disease Control and Prevention, Fort Collins, Colorado.

${ }^{2}$ Vector-Borne and Zoonotic Diseases, Arizona Department of Health Services, Phoenix, Arizona.

${ }^{3}$ National Wildlife Disease Program, Animal and Plant Health Inspection Services, Wildlife Services, United States Department of Agriculture, Fort Collins, Colorado.

${ }^{*}$ Present affiliation: University of Arizona, Tucson, Arizona.
} 
In the western United States, annual seroprevalence rates in coyotes are typically around 15\% (Barnes 1982), but can reach near $80 \%$ during an active plague epizootic (Poland et al. 1973). Such data have been used to spatially delineate plague risk areas (Willeberg et al. 1979, Barnes 1982). A recent study found $62.9 \%$ of positive coyote samples collected by passive surveillance to be within $1 \mathrm{~km}$ of human plague risk areas (Lowell et al. 2009). Fewer studies have discussed the annual variance in plague exposure in carnivores (Gese et al. 1997, Hoar et al. 2003). Geographical and temporal differences in seroprevalence rates have been attributed to plague prevalence rates in coyote prey (Gese et al. 1997). The abundance of $Y$. pestis susceptible prey, in turn, has been associated with meteorological variables such as temperature and rainfall patterns (Ernest et al. 2000).

Although state and local health and wildlife departments, the U.S. Department of Agriculture (USDA), and the CDC collect coyote blood samples, the association between rates of human infection and coyote seroprevalence rates has not been quantitatively established. Anecdotally, canine serological data reflect patterns in the rates of infection in humans (Archibald and Kunitz 1971, Barnes et al. 1988). In this study, we test for an association between coyote seroprevalence rates and human plague cases reported from four plague-endemic counties in Arizona, where enhanced surveillance activities were conducted from 1974 through 1998. We also investigate meteorological predictors of annual variation in coyote seroprevalence rates as a tool for identifying years with elevated plague risk.

\section{Materials and Methods}

\section{Study area}

Coyote blood samples were collected as part of a collaborative effort between the Arizona Department of Health Services (ADHS) and Wildlife Services to amass pathogen exposure data on predatory animals along the southern parts of Apache and Navajo counties and most of Coconino and Yavapai counties (shaded areas of Fig. 1). These plagueendemic areas are comprised of both high-use tourist destinations and ranchlands where coyotes are considered nuisance animals. The land-cover consists primarily of Rocky Mountain Ponderosa Pine Woodland, Colorado Plateau Piñon-Juniper Woodland, Mountain Basins Semi-Desert Shrub Steppe, and Mountain Basins Semi-Desert Grassland.

\section{Coyote data}

Between 1974 and 1998, about 2,276 (annual range: 21-206, median: 88) coyote blood samples (nobuto strips; Advantec MFS, Pleasanton, CA) were collected in Arizona and sent to the CDC (Fort Collins, CO), where they were tested for antibodies to $Y$. pestis using the passive hemaglutination assay (Chu 2000). A positive test result is indicative that the coyote survived infection by $Y$. pestis. Because coyotes maintain low titers for long periods (Barnes 1982), we assumed high antibody titers, 1:256 or greater, to be indicative of recent exposure. Using this elevated titer, 354 samples were positive (16\%; annual median $14.3 \%$, range $0 \%-65.6 \%$ ). This is compared to 806 positives at titers of 1:32 or greater (39.1\%) which is a more commonly used threshold and the lower limit of detection using nobuto strips.

\section{Human data}

Plague is a nationally notifiable disease and confirmation of a human case is defined as isolation of $Y$. pestis from a clinical specimen or a fourfold or greater change in paired (acute and convalescent) serum antibody titers to the F1 antigen (Poland and Dennis 1999). Because of the disease severity and mandatory reporting requirements, it is unlikely that many human cases go un-reported in the United States. Annual human plague case reports by county were obtained from the ADHS (http://azdhs.gov/phs/oids/vector/plague/stats.htm). For the same period the coyote surveillance program was in effect (1974-1998), 52 human cases were reported (median 2 cases per year, range $0-10$ ) in the four county study area. Three additional cases occurred during this time (in Gila Co., Mohave Co., and one acquired outside of Arizona) and were excluded from this study.

\section{Meteorological data}

In the absence of latitude and longitude coordinates for the blood sample collection locations, we extracted meteorological data from 80 randomly generated points in the area of interest (ArcGIS, ESRI, Redlands, CA). The mean distance between points was $15 \mathrm{~km}$ to facilitate unique pixel selection with respect to the $2.5 \operatorname{arcmin}\left(4 \mathrm{~km}^{2}\right)$ resolution climate data. The areas for the randomly selected points were limited to public lands (Bureau of Land Management, State Land, U.S. Fish and Wildlife Service, Military) in Coconino Co., Yavapai Co., and in the southern parts of Apache and Navajo counties consistent with where the coyote samples were most likely collected (Fig. 1).

Monthly average minimum and maximum temperature $\left({ }^{\circ} \mathrm{F}\right)$ and precipitation (inches) data for 1970-1998 were extracted from the online PRISM Data Explorer (http:// mole.nacse.org/prism/nn/; PRISM Climate Group, Oregon State University, Corvallis, OR). PRISM surfaces are derived from point measurements of meteorological data that are interpolated using algorithms to account for elevation and other geographic characteristics. Values for all 80 points were averaged to a single value per month of each year. Inverse associations between temperatures above $27^{\circ} \mathrm{C}\left(80.6^{\circ} \mathrm{F}\right)$ and plague activity have been previously described (Brooks 1917, Davis 1953, Cavanaugh and Marshall 1972, Cavanaugh and Williams 1977). Consequently, the annual number of degrees over $80.6^{\circ} \mathrm{F}$ was calculated by summing the total degrees above $80.6^{\circ} \mathrm{F}$ for each month of the year. Precipitation is thought to be important due to the effect of the trophic cascade and the foraging behavior of coyotes and rodents (Ernest et al. 2000). Total seasonal precipitation was also calculated (Winter: January-April, Fore-Summer: May-July, Monsoon: August and September, and Fall: October-December).

Because we were looking for meteorological predictors of annual variance in coyote seroprevalence rates, we also inspected monthly temperature and precipitation data for extreme values. Months with greater variability for either temperature (October and December minimum temperatures; March, April, May, June, and July maximum temperatures) or precipitation (cumulative January, February, and March) were identified for testing as independent variables.

A total of 21 variables were tested against the square root transformed percent of coyote titers above 1:256 to identify significant temporal lags up to 5 years for testing in the model. 


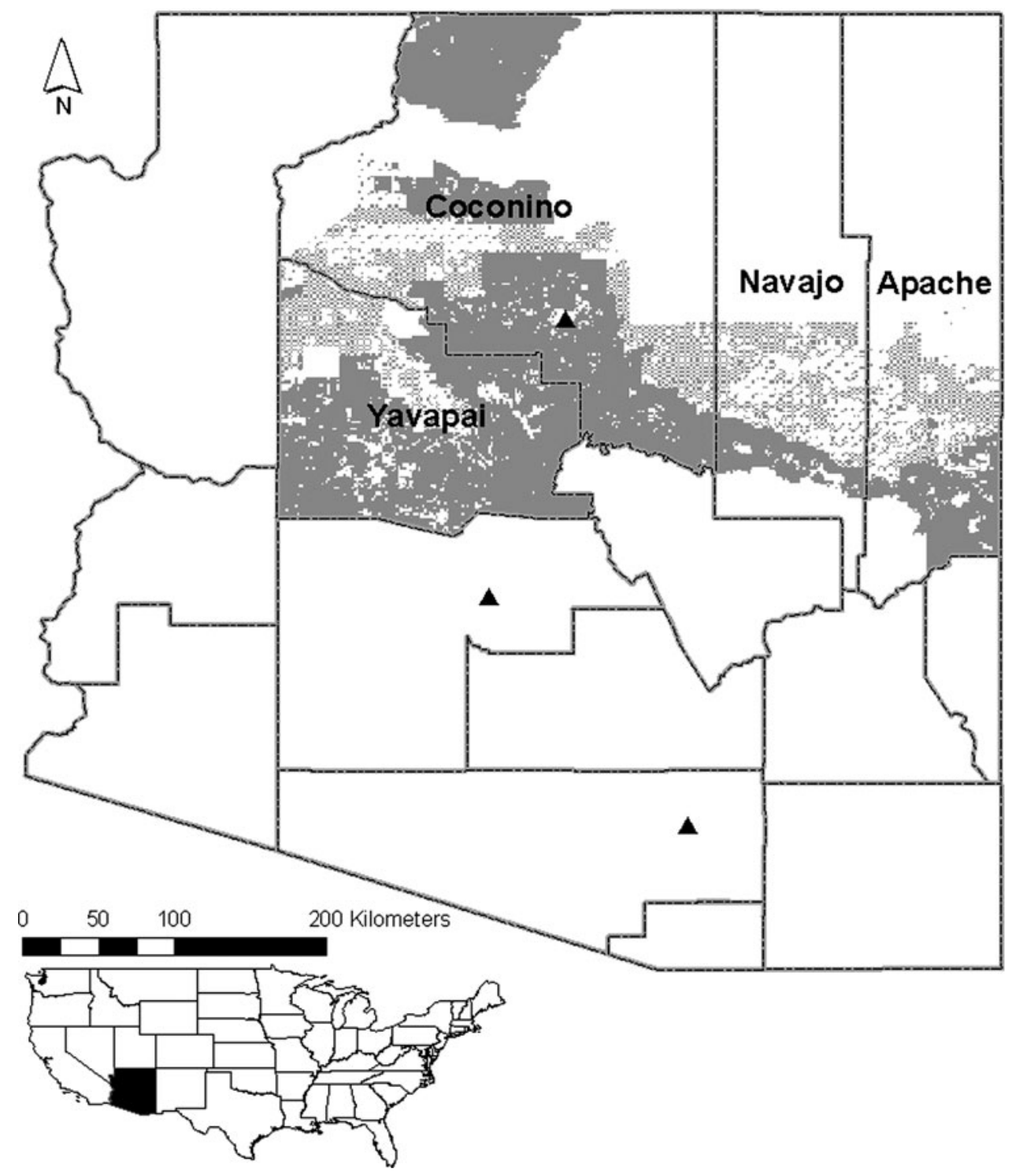

FIG. 1. Map of Arizona, United States, showing Yavapai, Coconino, Navajo, and Apache counties and an inset national map to show location of Arizona in the Southwest. Public lands, shading, are the most likely areas from whence the coyote data were acquired. For reference, the three most populated cities, Flagstaff, Phoenix, and Tucson (north to south), are shown.

Temporal lags allow for the possibility of predictive models, where meteorological data from 1 year should have a measureable effect on plague activity in subsequent years (Gage and Kosoy 2005). Seventeen possible variables were significantly correlated and tested in the model (Spearman correlation coefficient, $r_{\mathrm{s}}>0.3$ ).

\section{Analysis of association between coyote and human data}

We dichotomized the human case data at the median into "elevated human case years" (i.e., years with two or more human cases) or "average human case years" (i.e., years with one or no human cases). We used logistic regression to test whether elevated human case years were associated with annual seroprevalence in coyotes across all four counties. We then sought a threshold for the percent of coyote titers $\geq 1: 256$ tested to identify elevated human case years that would maximize sensitivity (i.e., the correct identification of elevated human case years) and specificity (i.e., the correct identification of average human cases years). In addition, positive (PPV) and negative predictive values (NPV) are reported as measures of the correctness of using coyote seroprevalence rates to identify elevated human years or average human case years, respectively.

\section{Modeling the association between coyote seroprevalence and meteorological data}

To model annual variation in coyote seroprevalence rates, we used forward stepwise linear regression. All variables were normally distributed (Shapiro-Wilk $W$ test for normal data $p \geq 0.12$ ). Each of the 17 possible predictors (Table 1) was tested in a univariate model. Predictors were added to the model based on improvements in the coefficient of determination $\left(r^{2}\right)$. Once the final predictors were determined, 
Table 1. Possible Predictors Tested in Model

Annual temperature minimum (3 year lag)

Annual temperature minimum (4 year lag)

Winter temperature minimum (previous year)

Winter temperature minimum (4 year lag)

Fore-Summer temperature minimum (previous year)

Fore-Summer temperature minimum (3 year lag)

Fall temperature minimum (previous year)

April temperature maximum (2 year lag)

April temperature maximum (3 year lag)

May temperature maximum (previous year)

July temperature maximum (current year)

Winter temperature maximum (4 year lag)

Total annual degrees over $80.6^{\circ} \mathrm{F}$ (current year)

Annual monthly precipitation average (previous year)

Total annual precipitation (previous year)

Winter precipitation (previous year)

Winter precipitation (3 year lag)

variables were tested for multicolinearity. Correlations $>0.9$ were considered indicative of multicolinearity and these variables were not included in the same model. The models were compared using Akaike Information Criterion, and variables were added until the difference in Akaike Information Criterion between models was $\leq 2$, indicating that the models were comparable and the more parsimonious model was selected (Burnham and Anderson 2002).

The most parsimonious model was evaluated using the leave-one-out cross-validation (LOOCV) method (Martens and Næs 1989, Efron and Tibshirani 1993), consisting of serial removal followed by replacement of each year to calculate the $r^{2}$. The LOOCV output was used to calculate a 95\% confidence interval (CI) for the $r^{2}$. Highly variable $r^{2}$ values indicated that the model was overly sensitive to specific years. If the $r^{2}$ of our model fell within the $95 \%$ CI calculated for the $r^{2}$, the model was considered stable.

We then compared the predictions derived from meteorological data with respect to both the observed coyote and human data. The meteorological-based model predictions of percent seropositive coyotes for each year were dichotomized at the determined threshold and compared with the observed coyote seroprevalence rates and with the dichotomized human data. Again, sensitivity, specificity, PPV, and NPV are presented as measures of the diagnostic value of the predicted coyote seroprevalence rates.

All statistical analyses were conducted in Stata v10.0 (StataCorp LP, College Station, TX). Data that were transformed to normal were back transformed for presentation.

\section{Results}

\section{Associations between coyote and human data}

A significant positive association between annual human cases and annual coyote seroprevalence rates (square root transformed for normal Shapiro-Wilk $W=0.96, Z=0.03$, $p=0.49$ ) was observed. For every percent increase in coyote seroprevalence rates, the odds of having an elevated plague year increased by 2.64 (95\% CI: $1.0-2.63 ; X^{2}=5.06, \mathrm{df}=1$, $p=0.03$; Fig. 2).

Classifying the coyote data as elevated when the percent positive (titers $\geq 1: 256$ ) for a given year was $>17 \%$ resulted in

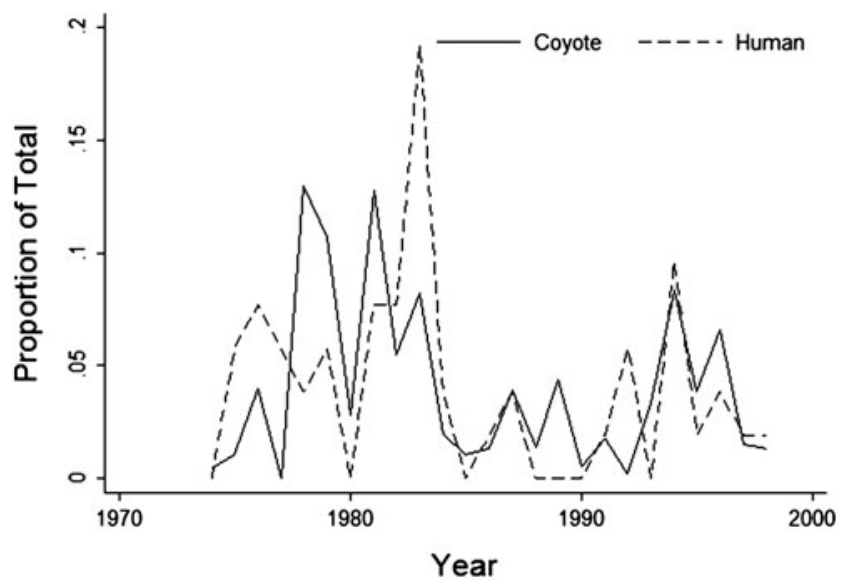

FIG. 2. Comparison of human cases and seropositive coyote samples by year. The y-axis is the annual proportion of total to facilitate comparing human (median per year $=2$ ) and coyote data (median per year $=14 \%$ ).

$76 \%$ agreement with the dichotomized human case years (elevated $=\geq 2$ cases; average $=1$ or no cases) (Table 2 ). For this relatively rare disease we were willing to accept a model with high specificity $(83.3 \%)$ and moderate sensitivity $(69.2 \%)$. That is, though some elevated human case years might not be identified we had greater confidence with respect to the ability to detect average human case years. The positive and negative predictive values were high $(81.8 \%$ and $71.4 \%$, respectively), indicating that the $17 \%$ threshold accurately identified years of average or elevated human cases.

\section{Coyote seroprevalence and meteorological data model}

The best forward stepwise linear regression model of interannual coyote seroprevalence included four variables: a positive association with the previous year's winter minimum temperature and the current year's maximum in July, and a negative association with the previous May's maximum temperature and the April maximum temperature 3 years

Table 2. Observed Annual Human Cases Dichotomized at the Median ${ }^{\mathrm{a}}$ Versus Observed Coyote $^{-}$ SEROPREVALENCE RATES ${ }^{\mathrm{b}}$

\begin{tabular}{llcc}
\hline & \multicolumn{2}{c}{ Observed human cases } \\
\cline { 3 - 4 } & & $\begin{array}{c}\text { Elevated } \\
(\geq 2)\end{array}$ & $\begin{array}{c}\text { Average } \\
(1 \text { or } 0)\end{array}$ \\
\hline Observed & Elevated $(\geq 17)$ & 9 & 2 \\
Coyote & Average $(<17 \%)$ & 4 & 10 \\
& Sn & & $69.2 \%(9 / 13)$ \\
& Sp & & $83.3 \%(10 / 12)$ \\
& PPV & & $81.8 \%(9 / 11)$ \\
& NPV & & $71.4 \%(10 / 14)$ \\
& Accuracy & & $76.0 \%(19 / 25)$ \\
\hline
\end{tabular}

${ }^{\mathrm{a}}$ Two or more cases per year $=$ elevated human case years

${ }^{b}$ Dichotomized where years where $17 \%$ or more of samples have titers of $\geq 1: 256$ are considered elevated.

$\mathrm{Sn}$, sensitivity; Sp, specificity; PPV, positive predictive value; NPV, negative predictive value; Accuracy, overall accuracy. 
Table 3. Model Comparison. Lags and Potential Predictors were Identified using Cross Correlation Comparison with the 25 Years of Annual Coyote Seroprevalence Rates (Square Root Transformed).

\begin{tabular}{|c|c|c|c|c|}
\hline Predictors & Coef. & $\mathrm{t}$ & $P>|t|$ & {$[95 \% \mathrm{CI}]$} \\
\hline \multicolumn{5}{|c|}{ Model $1\left(F_{(1,23)}=8.68 ; P=0.03 ; r^{2}=0.243 ; A I C=105\right)$} \\
\hline Previous May Tmax & -0.34 & -2.95 & 0.007 & $-0.58-0.10$ \\
\hline Constant & 29.68 & 3.40 & 0.002 & 11.647 .7 \\
\hline \multicolumn{5}{|c|}{ Model $2\left(F_{(2,22)}=8.52 ; P=0.002 ; r^{2}=0.385 ; A I C=100\right)$} \\
\hline Previous May Tmax & -0.37 & -3.48 & 0.002 & $-0.59-0.15$ \\
\hline Previous Winter Tmin & 0.51 & 2.52 & 0.020 & 0.090 .92 \\
\hline Constant & 16.50 & 9.45 & 0.095 & -3.1036 .11 \\
\hline \multicolumn{5}{|c|}{ Model $3\left(F_{(3,21)}=12.34 ; P<0.001 ; r^{2}=0.586 ; A I C=91\right)$} \\
\hline Previous May Tmax & -0.36 & -4.20 & 0.000 & $-0.54-0.18$ \\
\hline Previous Winter Tmin & 0.58 & 3.46 & 0.002 & 0.230 .92 \\
\hline 3 yr prior April Tmax & -0.26 & -3.42 & 0.003 & $-0.42-0.10$ \\
\hline Constant & 31.65 & 3.54 & 0.002 & 13.0850 .22 \\
\hline \multicolumn{5}{|c|}{ Model $4\left(F_{(4,20)}=14.88 ; P<0.001 ; r^{2}=0.698 ; A I C=84\right)$} \\
\hline Previous May Tmax & -0.35 & -4.78 & 0.000 & $-0.51-0.20$ \\
\hline Previous Winter Tmin & 0.53 & 3.69 & 0.001 & 0.220 .82 \\
\hline 3 yr prior April Tmax & -0.25 & -3.82 & 0.001 & $-0.39-0.11$ \\
\hline July Tmax & 0.41 & 2.97 & 0.008 & 0.120 .70 \\
\hline Constant & 31.65 & 3.54 & 0.002 & 13.0850 .22 \\
\hline
\end{tabular}

AIC, Akaike Information Criterion; CI, confidence interval.

prior $\left(\mathrm{F}_{(4,20)}=14.88 ; r^{2}=0.70, p<0.001\right.$; Table 3 for model comparison and Fig. 3 for predictions). This model was stable across the 25 years of data (LOOCV 95\% CI: 0.69-0.71).

Dichotomizing the predictions at an annual seroprevalence rate of $17 \%$ resulted in $81.8 \%$ of years being correctly classified as elevated and $85.7 \%$ as average (Table 4 and Fig. 3). Specificity, the number of average coyote seroprevalence years identified as average was $85.7 \%$. The sensitivity of the predictions derived from meteorological data was also high; $81.8 \%$ of elevated years were identified as elevated.

With respect to the observed human cases, the PPV of using predicted coyote seroprevalence to identify years with elevated human cases was $72.7 \%$ and the NPV was $64.3 \%$ (Table 4). Overall accuracy was $68 \%$ and sensitivity was moderate (61.5\% of elevated human case years were identified as elevated). Specificity was good $(75 \%)$.

\section{Discussion}

To our knowledge, this is the first time a temporal association between human plague cases and coyote seroprevalence rates has been quantifiably shown. In addition to quantifying this temporal association, we identified meteorological variables that were predictive of annual coyote seroprevalence rates.

The positive association between human cases and coyote seroprevalence rates was expected because coyotes prey upon plague-susceptible rodents over large areas and typically survive the infection and seroconvert (Archibald and Kunitz 1971, Willeberg et al. 1979, Gage et al. 1994). It is assumed that passive coyote sampling may detect less noticeable rodent epizootics, which pose a risk to humans from infectious flea bites encountered while outside or brought to the home by their companion animals (Eidson et al. 1988, Gould et al. 2008). Indeed, Holt et al. (2009) showed a significant association between plague activity in ground squirrels and passive coyote seroprevalence in California. In contrast to previous attempts to establish an association between human plague cases and coyote seroprevalence (Hopkins and Gresbrink 1982, Brinkerhoff et al. 2009), our approach of restricting positive titers to $\geq 1: 256$ in a highly endemic area with

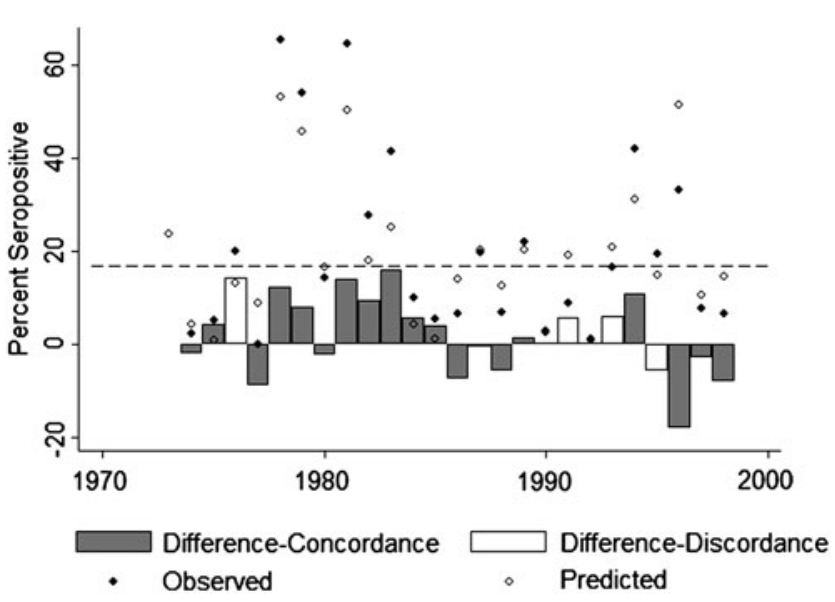

FIG. 3. Observed (dark circle) and predicted (open circle) coyote seroprevalence rates based on four meteorological variables (previous year's winter minimum temperature, current year July temperature maximum, previous May maximum temperature, and the 3-year prior April temperature maximum) identified by linear regression analysis $\left(\mathrm{F}_{(4,20)}=14.88 ; \mathrm{r}^{2}=0.70, p<0.001\right)$. Bars indicate the difference between observed and predicted values for the seroprevalence rates of coyote samples. With respect to the $17 \%$ threshold (dashed line), shaded bars indicate concordance where both the observed and predicted values were above or both were below the threshold and open bars indicate discordance where observed values were above the threshold, but were predicted to be below threshold or vice versa). 
Table 4. Summary for the Accuracy of Predictions Based on the Linear Regression Model Then Dichotomized at the $17 \%$ Seropositivity Threshold with Respect to the Observed Coyote and the Observed Human Data

\begin{tabular}{|c|c|c|c|c|c|}
\hline & & \multicolumn{2}{|c|}{ Observed: coyote } & \multicolumn{2}{|c|}{ Observed: human } \\
\hline & & Elevated & Nonelevated & Elevated & Nonelevated \\
\hline \multirow[t]{7}{*}{ Predicted Coyote } & Elevated & 9 & 2 & 8 & 3 \\
\hline & Nonelevated & 2 & 12 & 5 & 9 \\
\hline & Sn & $81.8 \%(9 / 11)$ & & $61.5 \%(8 / 13)$ & \\
\hline & Sp & $85.7 \%(12 / 14)$ & & $75.0 \%(9 / 12)$ & \\
\hline & PPV & $81.8 \%(9 / 11)$ & & $72.7 \%(8 / 11)$ & \\
\hline & NPV & $85.7 \%(12 / 14)$ & & $64.3 \%(9 / 14)$ & \\
\hline & Accuracy & $84 \%(21 / 25)$ & & $68 \%(17 / 25)$ & \\
\hline
\end{tabular}

enhanced surveillance likely influenced our ability to identify a correlation.

We were able to predict annual coyote seroprevalence rates (84\% accuracy at the $17 \%$ seropositivity threshold) using just four meteorological variables. Temperature and aboveaverage winter-spring precipitation have been shown to be associated with the annual occurrence of human plague cases (Parmenter et al. 1999, Enscore et al. 2002) presumably because of their influence on rodent reproduction and primary plant production (Davis 2005, Kastrud 2007). These same meteorological events markedly influence flea activity (Bacot and Martin 1924, Amin 1966, Olson 1969, Cavanaugh and Marshall 1972). The associations between warmer winter minimum temperatures and milder spring temperatures were likely due to the beneficial effects of milder weather on rodent and flea population growth.

An explanation for the positive association with maximum temperature in July of the current year was less apparent. We expected summers with temperatures that exceeded $27^{\circ} \mathrm{C}\left(80.6^{\circ} \mathrm{F}\right)$ to have a negative effect on plague occurrence (Bacot and Martin 1924, Cavanaugh and Williams 1977). However, we found a positive association with July maximums despite that average July maximum temperatures $\left(32^{\circ} \mathrm{C}\left[89.7^{\circ} \mathrm{F}\right]\right)$ were above this dampening threshold. This was similar to the findings of Enscore et al. (2002), who demonstrated a positive association between annual human cases and the number of days in a year with temperatures $>32.2^{\circ} \mathrm{C}\left(90^{\circ} \mathrm{F}\right)$, and a negative association with days over $35^{\circ} \mathrm{C}\left(95^{\circ} \mathrm{F}\right)$. Likewise, Ben Ari et al. (2008) used a higher temperature threshold (days $>37^{\circ} \mathrm{C}$ ) along with the annual human plague incidence per county and the Pacific Decadal Oscillation to model annual human plague cases in the western United States.

A possible explanation for the differences in how temperature relates to plague occurrence highlights the importance of microclimates and data resolution. For example, Brown et al. (2010) reported that elevation was important to the annual distribution of companion animal plague cases in New Mexico; higher elevations showed a more sporadic distribution of cases over the year, whereas lower elevations exhibited a distinct peak that collapsed when temperatures rose. Thus, while excessively high temperatures may reduce plague activity locally, the averaged monthly temperatures derived from $4 \mathrm{~km}^{2}$ pixels we used here may be too coarse a scale to accurately predict plague dynamics on a smaller scale.
The association between meteorological events and plague occurrence is specific to geographic location. A comparative study of meteorological predictors of prairie dog epidemics in Montana and Colorado found a strong association in Montana, but no measurable association in Colorado (Collinge et al. 2005). Likewise for human cases, models built for plague incidence in northeastern Arizona were not predictive in northwestern New Mexico though similar variables were significant in both models (Enscore et al. 2002). The $17 \%$ threshold we identified here is specific to this region in Arizona and should not be applied elsewhere without further testing.

Improving the spatial resolution of these data could improve the utility of coyote serporevalence data. Although the home range of transient coyotes can be $>100 \mathrm{~km}^{2}$ and occasional long distance travel (e.g., >300 km in 6 months) have been documented, mean home range sizes for adult coyotes is

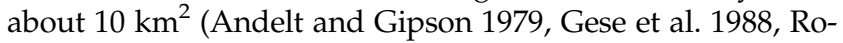
satte 2002). Meteorological data vary in space, especially within the diverse habitat of the Southwest (Parmenter et al. 1995, Sheppard et al. 2002). We expect a stronger association between coyote seroprevalence rates and meteorological predictors if latitude and longitude data were available for the samples.

We posit that, in the absence of intensive surveillance efforts such as the pet surveillance carried out by the New Mexico Department of Health [described in Brown et al. (2010)], coyote data will continue to be useful for the spatial delineation of plague risk and potentially will be useful for detection of meteorological related changes in the temporal distribution of plague. Identification of collection date and specific location of coyote serosurveillance samples would allow for more accurate predictions of increased risk. However, the data as collected from these four Arizona counties represent the best coyote surveillance data available. The collaboration between the ADHS and the USDA resulted in regular collections in a semiregular spatial distribution. Many of the other nobuto strips submitted to the CDC for processing have more sporadic sampling that is highly localized to limited areas. These latter data are less likely to be useful beyond periodic confirmation that plague is in an area.

\section{Acknowledgments}

We thank numerous employees of the USDA, Animal and Plant Health Inspection Services, Wildlife Services, for the 
collection of coyote samples. We thank John Young, CDC, NCEZID, DVBD, for helpful discussion. This research was supported in part by the appointment of Heidi E. Brown to the Research Participation Program at the CDC, NCEZID, DVBD, administered by the Oak Ridge Institute for Science and Education through an interagency agreement between the U.S. Department of Energy and the CDC.

\section{Disclosure Statement}

No competing financial interests exist.

\section{References}

Amin, OM. The fleas (Siphonaptera) of Egypt: distribution and seasonal dynamics of fleas infesting dogs of the Nile valley and delta. J Med Entomol 1966; 3:293-298.

Andelt, WF, Gipson, PS. Short communications: home range, activity, and daily movements of coyotes. J Wildl Manage 1979; 43:944-951.

Archibald, WS, Kunitz, SJ. Detection of plague by testing serums of dogs on the Navajo Reservation. HSMHA Health Rep 1971; 86:377-380.

Bacot, AW, Martin, CJ. The respective influence of temperture and moisture upon the survival of the rat flea (Xenopsylla cheopis) away from its host. J Hyg 1924; 23:98-105.

Barnes, AM, Quan, TJ, Beard, ML, Maupin, GO. Plague in American Indians, 1956-1987. Morb Mortal Wkly Rep 1988; 37:11-16.

Barnes, AM. Surveillance and control of bubonicplague in the United States. Symp Zool Soc Lond 1982; 50:237-270.

Ben Ari, T, Gershunov, A, Gage, KL, Snall, T, et al. Human plague in the USA: the importance of regional and local climate. Biol Lett 2008; 4:737-740.

Brinkerhoff, RJ, Collinge, SK, Bai, Y, Ray, C. Are carnivores universally good sentinels of plague? Vector Borne Zoonot Dis 2009; 9:491-497.

Brooks, RJ. The influence of saturation deficiency and of temperature on the course of epidemic plague. J Hyg 1917; 5:881899.

Brown, HE, Ettestad, P, Reynolds, P, Brown, TL, et al. Climatic predictors of the intra- and inter-annual distributions of plague cases in New Mexico based on 29 years of animalbased surveillance data. Am J Trop Med Hyg 2010; 82:95102.

Burnham, KP, Anderson, DR. Model Selection and Multi-Model Inference: A Practical Information-Theoretic Approach. New York: Springer-Verlag, 2002.

Cavanaugh, DC, Marshall, JD. The influence of climate on the seasonal prevalence of plague in the Republic of Vietnam. J Wildl Dis 1972; 8:85-94.

Cavanaugh, DC, Williams, JE. Plague: some ecological interrelationships. In: Traub, $\mathrm{R}$, Starcke, $\mathrm{H}$, eds. International Conference on Fleas. A.A. Balkema, Ashton Wold, Peterborough, United Kingdom, 1977.

Chu, MC. Laboratory manual of plague diagnostic tests. Atlanta, GA: Centers for Disease Control and Prevention, 2000.

Collinge, SK, Johnson, WC, Ray, C, Matchett, R, et al. Testing the generality of a trophic-cascade model for plague. EcoHealth 2005; 2:102-112.

Davis, DHS. Plague in Africa from 1935 to 1949: a survey of wild rodents in African territories. Bull World Health Organ 1953; 9:655-700.

Efron, B, Tibshirani, R. An Introduction to the Bootstrap. New York: Chapman \& Hall, 1993.
Eidson, M, Tierney, LA, Rollag, OJ, Becker, T, et al. Feline plague in New-Mexico-risk-factors and transmission to humans. Am J Public Health 1988; 78:1333-1335.

Enscore, RE, Biggerstaff, BJ, Brown, TL, Fulgham, RF, et al. Modeling relationships between climate and the frequency of human plague cases in the southwestern United States, 19601997. Am J Trop Med Hyg 2002; 66:186-196.

Ernest, SKM, Brown, JH, Parmenter, RR. Rodents, plants, and precipitation: spatial and temporal dynamics of consumers and resources. Oikos 2000; 88:470-482.

Gage, K, Montenieri, JA, Thomas, RE. The role of predators in the ecology, epidemiology, and surveillance of plague in the United States. In: Halverson, WS, Crabb, AC, eds. Proceedings of the 16th Vertebrate Pest Conference. Santa Clara, CA: University of California, 1994:2002-2206.

Gage, KL, Kosoy, MY. Natural history of plague: perspectives from more than a century of research. Annu Rev Entomol 2005; 50:505-528.

Gese, EM, Rongstad, OJ, Mytton, WR. Home range and habitat use of coyotes in Southeastern Colorado. J Wildl Manage 1988; 52:640-646.

Gese, EM, Schultz, RD, Johnson, MR, Williams, ES, et al. Serological survey for diseases in free-ranging coyotes (Canis latrans) in Yellowstone National Park, Wyoming. J Wildl Dis 1997; 33:47-56.

Gould, LH, Pape, J, Ettestad, P, Griffith, KS, Mead, PS. Dogassociated risk factors for human plague. Zoonoses Public Health 2008; 55:448-454.

Hoar, BR, Chomel, BB, Rolfe, DL, Chang, CC, et al. Spatial analysis of Yersinia pestis and Bartonella vinsonii subsp berkhoffii seroprevalence in California coyotes (Canis latrans). Prev Vet Med 2003; 56:299-311.

Holt, AC, Salkeld, DJ, Fritz, CL, Tucker, JR, Gong, P. Spatial analysis of plague in California: niche modeling predictions of the current distribution and potential response to climate change. Int J Health Geogr 2009; 8:38.

Hopkins, DD, Gresbrink, RA. Surveillance of sylvatic plague in oregon by serotesting carnivores. Am J Public Health 1982; 72:1295-1297.

Hull, HF, Montes, JM, Mann, JM. Plague masquerading as gastrointestinal illness. West J Med 1986; 145:485-487.

Lowell, JL, Eisen, RJ, Schotthoefer, AM, Xiaocheng, L, et al. Colorado animal-based plague surveillance systems: relationships between targeted animal species and prediction efficacy of areas at risk for humans. J Vector Ecol 2009; 34:22-31.

Martens, H, Næs, T. Multivariate calibration. Chichester, England; New York: Wiley, 1989.

MMWR. Human plague-four states, 2006. MMWR 2006; 55:940-943.

Olson, WP. Rat-flea indices, rainfall, and plague outbreaks in Vietnam, with emphasis on the Pleiku area. Am J Trop Med Hyg 1969; 18:621-628.

Parmenter, RR, Brantley, SL, Brown, JH, Crawford, CS, et al. Diversity of animal communities on southwestern rangelands: species patterns, habitat relationship and land management. In: West, NE, ed. Biodiversity of Rangelands: Natural Resources and Environmental Issues. Logan, UT: Utah State University, 1995:50-71.

Parmenter, RR, Yadav, EP, Parmenter, CA, Ettestad, P, Gage, KL. Incidence of plague associated with increased winterspring precipitation in New Mexico. Am J Trop Med Hyg 1999; 61:814-821.

Poland, JD, Barnes, AM, Herman, JJ. Human bubonic plague from exposure to a naturally infected wild carnivore. Am J Epidemiol 1973; 97:332-337. 
Poland, JD, Dennis, DT. Diagnosis and clinical manifestation. Plague Manual: Epidemiology, Distribution, Surveillance and Control. Geneva: World Health Organization, 1999: 43-53.

Rosatte, RC. Long distance movement by a Coyote, Canis latrans, and Red Fox, Vulpes vulpes, in Ontario: implications for disease-spread. Can Field-Nat 2002; 116:129-131.

Salkeld, DJ, Stapp, P. Seroprevalence rates and transmission of plague (Yersinia pestis) in mammalian carnivores. Vector Borne Zoonot Dis 2006; 6:231-239.

Sheppard, PR, Comrie, AC, Packin, GD, Angersbach, K, Hughes, MK. The climate of the US Southwest. Clim Res 2002; 21:219-238.

von Reyn, CF, Barnes, AM, Weber, NS, Quan, T, Dean, WJ. Bubonic plague from direct exposure to a naturally infected wild coyote. Am J Trop Med Hyg 1976; 25:626-629.
Willeberg, PW, Ruppanner, R, Behymer, DE, Higa, HH, et al. Epidemiologic survey of sylvatic plague by serotesting coyote sentinels with enzyme immunoassay. Am J Epidemiol 1979; 110:328-334.

Wong, D, Wild, MA, Walburger, MA, Higgins, CL, et al. Primary pneumonic plague contracted from a mountain lion carcass. Clin Infect Dis 2009; 49:E33-E38.

Address correspondence to: Heidi E. Brown School of Geography and Development The University of Arizona 1103 E 2nd Street Harvill Room 405 Tucson, AZ 85721

E-mail: heidibrown@email.arizona.edu 